\title{
Investigating Difficulty Order of Certain English Grammar Features in an Iranian EFL Setting
}

\author{
Ali Panah Dehghani ${ }^{1}$, Mohammad Sadegh Bagheri ${ }^{1}$, Firooz Sadighi ${ }^{1} \&$ Ghasem Tayyebi ${ }^{2}$ \\ ${ }^{1}$ Department of English, Shiraz Branch, Islamic Azad University, Shiraz, Iran \\ ${ }^{2}$ Department of English, Kazerun Branch, Islamic Azad University, Kazerun, Iran \\ Correspondence: Mohammad Sadegh Bagheri, Department of English, Shiraz Branch, Islamic Azad University, \\ Shiraz, Iran. E-mail: bagheries@gmail.com
}

\author{
Received: September 16, 2016 Accepted: October 12, 2016 Online Published: November 23, 2016 \\ doi:10.5539/ijel.v6n6p209 \\ URL: http://dx.doi.org/10.5539/ijel.v6n6p209
}

\begin{abstract}
The English grammar is usually taught to undergraduate EFL learners in Iran during the first academic year. It may be supposed that they have acquired a good mastery of the English grammar as they are on the verge of graduation. At the same time, it may be assumed that some English grammar features are more difficult/less difficult than others for the EFL learners to master. This study, therefore, attempts to find out which English grammar features are more difficult/less difficult than others for Iranian undergraduate EFL learners. 125 Iranian undergraduate senior EFL learners took part in this study and responded to the English grammar test. Moreover, some experienced English instructors were asked to rate the difficulty of the given English grammar features. The data were collected and analyzed which revealed that some English grammar features were more difficult and some were less difficult than others for the EFL learners. The obtained difficulty order determined by the EFL learners and the one obtained according to the instructors' perceptions were compared. Some similarities/overlaps and differences were found to exist in the rank orders of the features for the two groups. The findings of the study may be beneficial to syllabus designers, material developers, instructors and EFL learners.
\end{abstract}

Keywords: EFL learners; undergraduate; grammar features; difficulty order; instructors' perceptions

\section{Introduction}

English as the most frequently taught second and foreign language in the world has made many researchers investigate more and more about the challenges language learners face. This has led to studying different approaches and techniques that help facilitate the process of learning different aspects of a particular language, one of which is grammar. Grammar is a key component of a language. "Grammar, as a means of communication, refers to the overall unconscious knowledge of a native speaker of a particular language" (Sadighi, 2008, p. 1). Instructors, in addition to knowledge of grammar, should have a good command of methodologies and techniques to facilitate grammar learning for language learners.

All aspects of language including vocabulary and grammar play essential roles in learning a language. In order to be fluent and accurate in a particular language, grammar cannot be neglected even though vocabulary may play a more important role. It is possible to say something in a particular language without adequate knowledge of grammar, but without proper knowledge of lexemes communication will be hindered. These two aspects function as the building blocks of any language for learners to be accurate and fluent. Zhang (2009) argues that grammar and vocabulary form the infrastructure of the English language. "It is exact that putting grammar in the foreground in second language teaching, because language knowledge of grammar and vocabulary is the base of English language" (Zhang 2009, p. 184). Learning the grammar of a particular language, is different from learning the vocabulary of that language; it is possible to learn some words in isolated lists without direct supervision of instructors, but the task of learning grammar is more complex and sometimes it is impossible to learn a particular point, in EFL settings, without explicit instruction. That is, for EFL learners, instruction of grammar seems to be vital, whether implicit or explicit. Grammar, hence, is an important component for language learners to master.

The matter of learning a language has always been the focus of attention by language learners. A language learner has to be equipped with the grammatical knowledge of the language to be able to communicate 
effectively and to be a competent member. In EFL settings, since learners are not in a natural environment, the process of grammar learning is more difficult. The importance of learning grammar in both receptive and productive skills has made many EFL learners adhere to grammar books, guided activities and exercises to increase their knowledge. Since grammar is an important part of language and it is within the body of language, separating this element and teaching it apart from the language, may result in failure. That is, EFL learners may learn some particular grammatical aspects and categories in isolation, but they may not be able to use the taught rules in real world contexts. Moreover, the existence or non- existence of a particular grammatical feature in the mother tongue may affect mastering of that feature in EFL context; learning an element which is absent in L1, may be more difficult for EFL learners.

Among the main reasons for learning grammar, after covering some literature reviews emphasizing the role and importance of grammar in language learning, the following seems worth mentioning: Knowledge of grammar

- allows a clear communication (although a good command of grammatical knowledge does not imply a good communication, knowledge of grammar is very crucial in communication of meaning)

- brings reputation when communicating with others

- helps individuals achieve self-confidence (inadequate knowledge of grammar affects EFL learners' self-confidence and autonomy, and as a result, it may hinder communication)

- $\quad$ affects learning of other skills and sub-skills

Sawir (2005) maintains that grammar is the most difficult area in practicing English, and that knowing the structure of the grammar enables language learners to speak a lot. Sawir believes that "Despite the great emphasis on the teaching of grammatical aspects at school, the students still find it a difficult aspect of English to learn, then and now" (p. 575). Wang. Sh (2010) states that it is the grammar of the language that enables us to talk about language. "Knowing about grammar also helps us understand what makes sentences and paragraphs clear, interesting and precise. Grammar can be part of literature discussions when we and our students closely read the sentences in poetry and stories" (pp. 313-314). Widodo (2006) argues that knowledge of grammar and structure enables language learners to put their ideas into words and let them communicate with others. Moreover, as Widodo (2006) states, grammar plays a role in learning vocabulary; “...grammar provides a pathway to learners how some lexical items should be combined into a good sentence so that meaningful and communicative statements or expressions can be formed" (p. 122).

Nassaji \& Fotos (2012) emphasize the significant role of grammar in language teaching, and the way of teaching grammar appropriately. Wang. F, (2010) recognizes that grammar is necessary to be taught by arguing that grammar is the skeleton of language proficiency without which language does not make sense. "The fact is that grammar ... still plays a big part in what many teachers, administrators, and parents consider to be basic literacy, grammar cannot be separated from the language" (Wang. Sh, 2010, p. 316). Therefore, grammar is fundamental in learning/acquiring a particular language. Not all grammar features may be at the same level of difficulty; some may be more difficult than others and take more time to consolidate.

Different researchers have used different terminologies/labels to refer to different components of the English grammar; grammar points (Graus \& Coppen, 2015), grammatical category (Ahangari \& Barghi (2012), grammar features (Shiu, 2011, p. 47), grammatical aspect (Darus \& Subramaniam, 2009, p. 486), area of grammar (Scheffler, 2008, p. 8), "grammatical structures" as well as "grammar features" (Ellis, 2006, pp. 454, 457, 458), feature/category (Chuang, 2005, p. 27). The researcher, therefore, for the current study benefited from such studies and used the term grammar feature to address different components of the English grammar.

\subsection{Objectives of the Study}

The current study aimed at recognizing the most difficult English grammatical features for Iranian undergraduate senior EFL students. This may help teachers and EFL learners to spend more time on the problematic features and seek remedies. Furthermore, it attempted to find out any similarities and differences between the difficulty order obtained by the EFL learners and that obtained according to instructors' perceptions.

\subsection{Research Questions and Hypothesis}

1) What is the order of difficulty of the given English grammatical features for Iranian undergraduate senior EFL learners?

2) Is there any difference between the instructors' perceptions and participants' performances on the difficulty order of the given English grammar features? 
$\mathrm{H}_{0}$ : There is no difference between the instructors' perceptions and participants' performances on the difficulty order of the given English grammar features.

\section{Literature Review}

Parts of the findings of a study by Saaristo (2015), concerning the significant role of grammar in language teaching and learning, revealed that many of the participants claimed that grammar is very important in language studies. Some students expressed fairly important role of grammar in teaching and learning a language; using language in addition to vocabulary was also claimed to be important. Some others claimed that grammar is not very important, and yet others provided no answers. In another study, Nan (2015) introduces linguistic and storytelling modes of grammar teaching/learning. As Nan argues, linguistic mode emphasizes the importance of knowledge of the rules and the reason why in different contexts there are different sentence formations. According to Nan, instruction of grammar through story-telling is very conducive; this technique can be especially fruitful for EFL beginners.

Graus \& Coppen (2015) argue that there are some determining factors for difficulty of grammar: "(1) grammar feature (formal and functional complexity); (2) pedagogical arrangement; (3) teacher quality; and (4) learner characteristics" (p. 101). In other words, they believe that difficulty of grammar feature is affected by some factors including "formal and functional complexity and pedagogical rule difficulty, both of which interact with learner characteristics" (p. 106). By learners' characteristics, they mean individual differences which encompass factors such as motivation, gender, and background knowledge. Pedagogical implication concerns with method, practice, complexity of rules, materials' quality, and the like. As they argue, the difficulty of a particular grammar feature can be a matter of learners' L1, ability or proficiency, and developmental stage as well as aptitude. They devised a questionnaire and chose three topics related to grammar. The selection criterion was based on the analysis of the grammar points covered in some- best-selling English grammar course-books series in the Netherlands. Then, they selected 31 grammar points (Table 1); the selection of the 31 grammar points was also in accordance with the estimates of some experienced English teachers. They firstly asked the participants to check the difficulty of the given grammar points (31 grammar points).

Table 1. Grammar points (Graus \& Coppen, 2015, p. 110)

\begin{tabular}{lll}
\hline Tense and aspect & Word order & Determiners/quantifiers \\
\hline Present simple & Transformation & Demonstrative determiners \\
Present continuous & Negations (do support) & Interrogative determiners \\
Past simple & Questions (do support) & Possessive determiners \\
Past continuous & Negations (auxiliaries) & Definite article + school, ... \\
Present perfect & Questions (auxiliaries) & O Indefinite article + profession \\
Present perfect continuous & Adverbials of time & Ordinal numbers \\
Past perfect & Adverbials of place & Quantifying Phrases \\
Future: will/shall & Adverbials of place and Time & Some/any \\
Future: to be going to & Adverbs of frequency & Little/ few \\
Future: present simple & & Much/many \\
Future: present continuous & & Genitive \\
Future continuous & & \\
\hline
\end{tabular}

Then, in the second part of the study, they investigated the cause of grammar difficulty and chose nine grammar points among the given 31 points. They asked the participants to indicate the factors affecting difficulty of the given grammar points, by considering the provided factors including complexity of form/use, L1, and the like. They found, as a part of the study, that first and second-year undergraduates considered learner characteristics as affecting factors for grammar difficulty, while third and fourth -year undergraduates as well as post graduate students (with at least 2 years experiences as English teachers) found pedagogical arrangement as determining factor in grammar difficulty.

Shiu (2011) conducted a study on EFL learners' perception of grammatical difficulty and examined twenty selected features of grammar through a questionnaire, and found that some features were more difficult, for the participants, than others to learn. Shiu concluded that some of the twenty features including clauses embedded questions, prepositions, real conditional, participial constructions, and unreal conditionals were perceived by the participants of the study as the most difficult. At the same time, it was found that negation, third person -s, 
present progressive, simple past-ed, wh-questions, and modal auxiliaries, were the least difficult items for the participants of the study.

It was found that the participants' perceptions of difficulty of grammar were in accordance with whether the articulations of rules were easy or difficult. That is, it was articulation of the rules that affected the participants' perceptions of grammar difficulty. It was also found that several factors affect the perception of grammatical difficulty such as individuals' experience of grammar learning, their first and second language knowledge, and L1 transfer.

Darus \& Subramaniam (2009) conducted a study to determine the grammatical mistakes of Malaysian EFL learners, males and females, in essay writing. The results revealed the most common and the most problematic aspects of English grammar for the participants. A complete list containing types of grammatical error committed by the participants is given below. The results indicated that although the participants had a weak knowledge of vocabulary in writing essays, the main problems they faced in writing their essays were basically rooted in the lack of English grammar knowledge, covering different aspects of English grammar, as shown below.

Table 2. The most problematic aspects (Darus and Subramaniam, 2009, p. 490)

\begin{tabular}{ll}
\hline & Grammatical aspects \\
\hline 1 & Singular/Plural Form \\
2 & Verb Tense \\
3 & Word Choice \\
4 & Preposition \\
5 & Subject/Verb Agreement \\
6 & Word Order \\
7 & Article \\
8 & Missing Space \\
9 & Word Form \\
10 & Spelling \\
11 & Verb Form \\
12 & Capitalization \\
13 & Wrong/Misused Word \\
14 & Missing word \\
15 & Redundancy \\
\hline
\end{tabular}

Scheffler (2008) in another study on Polish adult learners of English asked a group of the participants to determine the difficulty level of the given grammatical items. The difficulty of the given English grammatical areas was found to be as follows:

Table 3. Grammar difficulty from the participants' viewpoints (Scheffler, 2008, p. 4)

\begin{tabular}{ll}
\hline & Grammar areas \\
\hline 1 & Tenses \\
2 & Prepositions \\
3 & -ing forms and infinitives \\
4 & Modal verbs \\
5 & Conditional sentences \\
6 & Reported speech \\
7 & Passive voice \\
8 & Articles \\
9 & Nouns \\
10 & Pronouns \\
11 & Adjectives and adverbs \\
\hline
\end{tabular}

Table 3, represents the difficulty of the English grammar areas, from the most to the least difficult, according to the participants' perceptions. Scheffler (2008) also asked another group of Polish learners of English to determine which grammar areas they think are useful to be taught. The results indicated some overlaps between the obtained results. 
Table 4. Usefulness of grammar instruction from the participants' viewpoints (Scheffler, 2008, p. 4)

\begin{tabular}{ll}
\hline & Grammar areas \\
\hline 1 & Tenses \\
2 & Modal verbs \\
3 & Conditional sentences \\
4 & Passive voice \\
5 & Reported speech \\
6 & -ing forms and infinitives \\
7 & Prepositions \\
8 & Articles \\
9 & Nouns \\
10 & Adjectives and adverbs \\
11 & Pronouns \\
\hline
\end{tabular}

It was found that some areas such as tenses, modal verbs, and conditional sentences were on the top of both lists of difficult areas and useful instruction areas. At the same time, some other areas including pronouns and adjectives and adverbs were perceived as less difficult and less useful. For 'prepositions' and '-ing forms and infinitives', no overlaps were seen. The general level of difficulty and usefulness of instruction is given below.

Table 5. Level of difficulty and usefulness of instruction (Scheffler, 2008, p. 5)

\begin{tabular}{ll}
\hline & Grammar area \\
\hline 1 & Tenses \\
2 & Modal verbs, conditional sentences, reported speech and passive voice \\
3 & Articles, nouns, and pronouns \\
4 & Adjectives and adverbs \\
\hline
\end{tabular}

According to Feike (2011) the given hierarchy is likely affected by the participants' proficiency and their first language knowledge.

To find out the grammatical mistakes Malaysian EFL learners commit in writing essays, Maros \& Salehuddin (2007) conducted a study and it was revealed that, in spite of studying English for six years, the participants had problems in using the correct form of the English grammar in their writing. The findings indicated that the main sources of errors were: correct forms of articles, subject-verb agreement, the use of determiners, omission of third person singular " $s$ ", and the correct forms as well as the omission of copula "be".

In another study, Ellis (2006) investigated seventeen grammar structures to re-examine which features are more difficult than others.

Table 6. Ellis's list of English grammar structure (2006, pp. 442-443)

\begin{tabular}{lll}
\hline & Grammar structure & \\
\hline Verb complement (e.g., v + to) & Yes/no questions & Adverb placement \\
3rd person $-\mathrm{s}$ & Comparative & Question tags \\
Plural $-\mathrm{s}$ & Unreal conditionals & Since/for \\
Indefinite article & Modals & Dative alternation \\
Possessive $-\mathrm{s}$ & Ergative verbs & Relative clauses \\
Regular past tense -ed & Embedded questions & \\
\hline
\end{tabular}

Ellis (2006) found a relationship between explicit and implicit knowledge; those structures which were easy through implicit knowledge were usually difficult in terms of explicit knowledge and sometimes this situation was found to be vice versa. For the two types of knowledge, some structures were found to be approximately the same in terms of difficulty, and some features were found to be either difficult or easy. In using these two types of knowledge, no correlation was found between the rank orders of difficulty of the grammar structures.

In sum, some studies have been conducted to investigate the hierarchical order of English grammatical features for different EFL learners all around the world, with identical or different results. These studies indicate the 
importance of grammar and the difficulty of grammar for EFL learners. Learners' level of education, experience, age, setting, gender, motivation, aptitude, and the same may affect the difficulty of grammar.

\section{Method}

Participants, instruments, and procedures of the current study are discussed in this section.

\subsection{Participants}

The participants of the study were 125 undergraduate senior EFL learners from different universities and higher education institutes. They were mainly 22-25 years old, males and females. They were studying English translation, teaching, and literature. They had already passed grammar courses, and had studied English grammar. 12 experienced English teachers were also involved in the current study to express their opinions concerning the difficulty level of the English grammar features.

\subsection{Instruments}

Oxford Placement Test (2007) and a researcher-developed test of English grammar were the two instruments used in this study. Oxford Placement Test was administered to ensure that the participants were intermediate EFL learners. The researcher, then, drawing on the works by Graus \& Coppen (2015) as well as that of Scheffler (2008), Ellis (2006), considering some other previously carried out studies, and consulting some frequently used English grammar books in Iran, provided a list of English grammar features and asked some experienced teachers to signify the difficulty of the given features. Since it was beyond the scope of the current study to include all the features, the researcher included the first twelve more difficult features. For each feature 5 questions were raised, making a sixty-item grammar test. The selection of test items was in accordance with easy, moderate, and difficult items. The items of the grammar test were adopted from some previously covered books. The reliability of the test $(\mathrm{r}=.71)$ was determined through piloting study and using Cronbach's alpha. Some subject matter experts checked and approved the validity of the grammar test.

Table 7. The given twelve English grammar features

\begin{tabular}{lll}
\hline English grammar features & & \\
\hline Tense & Article & Determiner \\
Passive & Conditional & Relative clause \\
Preposition & Conjunction & Causative \\
Verbals & Reported speech & Tag question \\
\hline
\end{tabular}

\subsection{Procedures}

Since it was boring for the participants to respond to the placement and grammar tests simultaneously, the researcher administered them on separate occasions. To detect and exclude non-senior students, the participants were asked to specify if they were sophomore, junior, or senior students. The researcher ensured the participants that their performances on the tests are highly confidential. The participants were asked to respond to the test by relying on their own knowledge, without consulting any resources. The provided English grammar features were also given to some experienced teachers to rate on a Likert scale from very easy to very difficult. That is, the difficulty of the features was determined according to the instructors' viewpoints; they were asked to rate the features as very easy, easy, moderate, difficult and very difficult based on their perceptions.

\section{Data analysis and Results}

a) A one-way ANOVA within groups to analyze the participants' performances on the given English grammar features.

b) Post-hoc comparisons to determine if the differences between the given features were statistically significant.

The data were collected and analyzed. The order of difficulty of the provided English grammar features for all the participants was also determined. The obtained results were, then, compared with that obtained from the instructors' perceptions to investigate if there were any similarities and differences.

\subsection{The Difficulty Order of the Given English Grammar Features}

Through a one-way ANOVA within groups the participants' performances on the given English grammar features were determined. The mean scores and the standard deviations of the features were also determined. 
Table 8 . The order of difficulty of the English grammatical features

\begin{tabular}{llll}
\hline Grammar features & Mean & Std. Deviation & Std. Error \\
\hline 1- Causative & 1.9680 & 1.19769 & .10712 \\
2- Reported speech & 2.6240 & 1.20258 & .10756 \\
3- Article & 2.7120 & 1.01454 & .09074 \\
4- Conditional & 2.7760 & 1.24346 & .11122 \\
5- Passive & 2.8640 & 1.37573 & .12305 \\
6- Verbal & 2.9760 & 1.16026 & .10378 \\
7- Preposition & 3.0160 & 1.11431 & .09967 \\
8- Tag question & 3.0960 & 1.12468 & .10742 \\
9- Conjunction & 3.0960 & 1.20097 & .10059 \\
10- Tense & 3.2960 & 1.21166 & .10837 \\
11- Determiner & 3.5680 & 1.05751 & .09459 \\
12- Relative clause & 3.9440 & 1.01841 & .09109 \\
\hline
\end{tabular}

Table 8, represents the order of difficulty of the given English grammar features for Iranian undergraduate EFL learners majoring in English. By comparing the obtained mean scores, the difficulty order of the features was determined. It was identified that which features were more difficult than others for the Iranian EFL learners to consolidate. The mean scores ranged from 1.97 (causatives) to 3.94 (relative clauses). It was revealed that most of the mean scores ranged from 2.62 to 2.97 (five cases), and from 3.00 to 3.29 (four cases). From 3.56 to 4.00 , there were two mean scores, and finally one mean score was shown to be lower than 2.00 . To have a better understanding of the order of difficulty of the grammar features, it may be plausible to divide the Table into two halves: from 1-6 as the first/upper half, and from 7-12 as the second/lower half.

In the first/upper half of the table, for the given grammar features, it was revealed that the order of difficulty starts from causatives, as the most difficult feature. Reported speech was shown to be the second most difficult feature for the participants of the study, followed by articles, conditional sentences, passives, and verbals. For the second half of the table, prepositions, tag questions, conjunctions, tenses, determiners, and finally relative clauses form the hierarchy for the given features. It is to be noted that tag question and conjunction features were shown to be at the same level of difficulty with identical mean scores, but with different SDs. The obtained results represent the overall difficulty order of the given English grammar features for the participants of the study regardless of their gender. Clearly, causative proved to be the most difficult $(\mathrm{M}=1.96)$ and relative clause $(\mathrm{M}=3.94)$ the less difficult English grammar features.

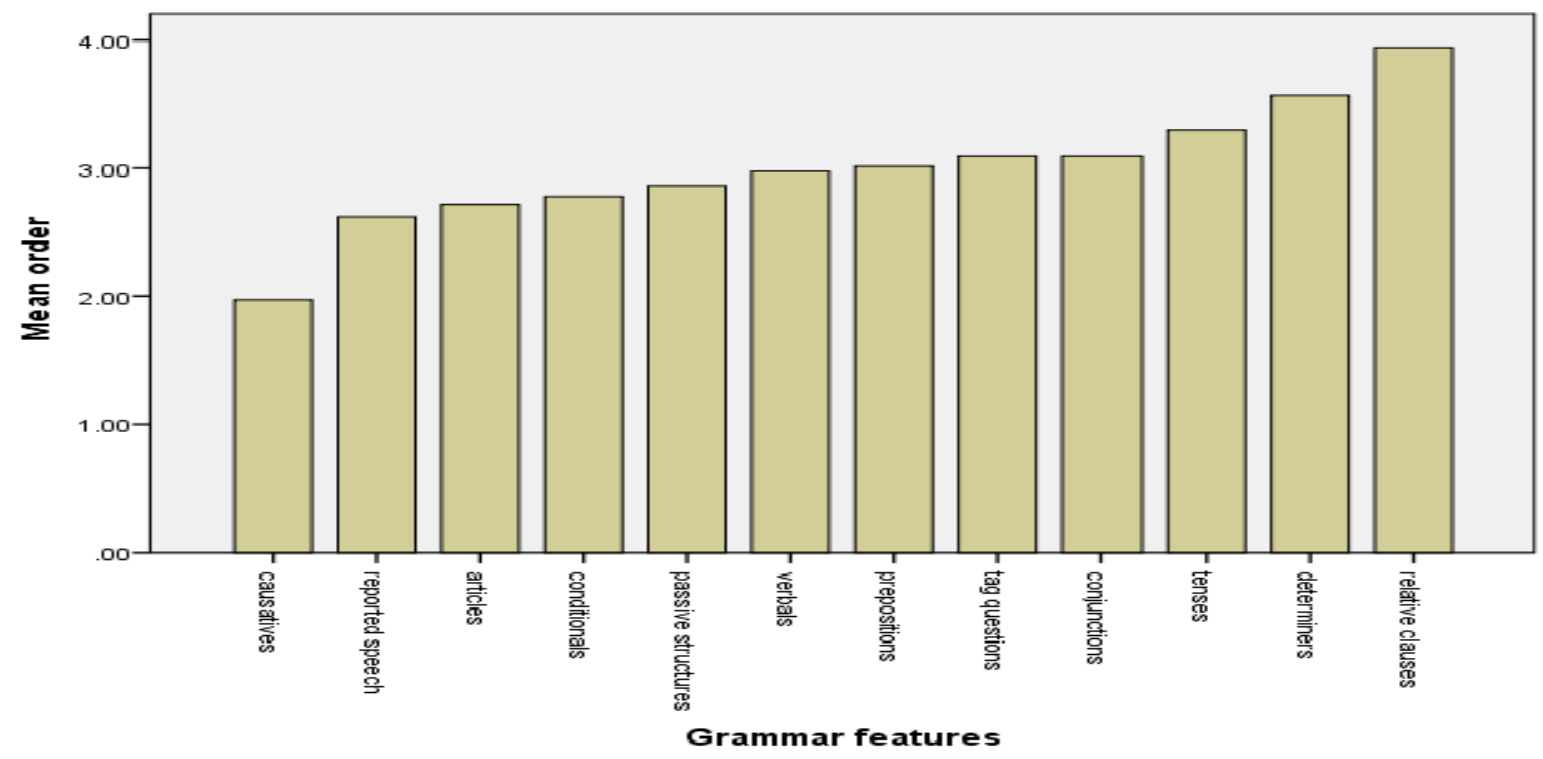

Figure 1. The order of difficulty of the given English grammar features

Figure 1, represents the obtained mean scores on the twelve English grammar features by the participants, based on Table 8 . The obtained mean scores ranged mainly from 2.50 to 3.50 . 
Table 9. Multivariate tests for the EFL learners' performances on the given features

\begin{tabular}{|c|c|c|c|c|c|c|c|}
\hline Effect & & Value & $\mathrm{F}$ & Hypothesis df & Error df & Sig. & Partial Eta Squared \\
\hline & Pillai's Trace & .779 & 36.583 & 11.000 & 114.000 & .000 & .779 \\
\hline & Wilks’ Lambda & .221 & 36.583 & 11.000 & 114.000 & .000 & .779 \\
\hline & Hotelling's Trace & 3.530 & 36.583 & 11.000 & 114.000 & .000 & .779 \\
\hline & Roy's Largest Root & 3.530 & 36.583 & 11.000 & 114.000 & .000 & .779 \\
\hline
\end{tabular}

The value for Wilks' Lambda was shown to be .22 with the probability value of .000 , which suggested that the $\mathrm{p}$ value was less than $.05,(\mathrm{p}=0.00)$. Wilks' Lambda $=.22, \mathrm{~F}(11,114)=36.58, \mathrm{p}<.001$, multivariate partial eta squared $=.78$. Therefore, there were statistically significant differences among the mean scores of the given English grammar features.

To determine which features differed significantly from the others post-hoc comparisons, using Bonferroni, was run the results of which are given in the following section. The p value (Sig) is given for those features which were statistically significantly different. The mean scores and standard deviations are given in Table 8 .

Table 10. Pair-wise comparison for statistical significant differences between the given features

\begin{tabular}{|c|c|c|c|c|c|c|c|c|c|c|c|c|}
\hline & $\begin{array}{l}\stackrel{-1}{\oplus} \\
\stackrel{9}{0} \\
\stackrel{0}{0}\end{array}$ & 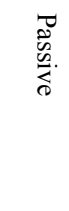 & 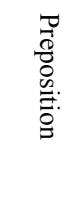 & $\begin{array}{l}\stackrel{\Phi}{\Phi} \\
\stackrel{\Phi}{\mathscr{D}}\end{array}$ & $\frac{\gtrless}{\frac{2}{0}}$ & 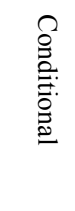 & 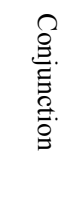 & 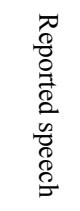 & 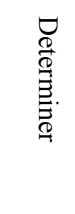 & 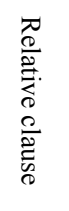 & 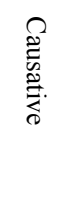 & 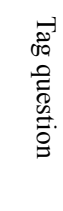 \\
\hline Tense & & & & & 001. & 015. & & .000 & & .000 & .000 & \\
\hline Passive & & & & & & & & & .000 & .000 & .000 & \\
\hline Preposition & & & & & & & & & .001 & .000 & .000 & \\
\hline Verbal & & & & & & & & & .000 & .000 & .000 & \\
\hline Article & .001 & & & & & & & & .000 & .000 & .000 & \\
\hline Conditional & .015 & & & & & & & & .000 & .000 & .000 & \\
\hline Conjunction & & & & & & & & & .019 & .000 & .000 & \\
\hline Reported speech & .000 & & & & & & & & .000 & .000 & .000 & .017 \\
\hline Determiner & & .000 & .001 & .000 & .000 & .000 & .019 & .000 & & & .000 & .013 \\
\hline Relative clause & .000 & .000 & .000 & .000 & .000 & .000 & .000 & .000 & & & .000 & .000 \\
\hline Causative & .000 & .000 & .000 & .000 & .000 & .000 & .000 & .000 & .000 & .000 & .000 & .000 \\
\hline Tag question & & & & & & & & .017 & .013 & .000 & .000 & \\
\hline
\end{tabular}

It was shown that when comparing "tense" with the remaining English grammatical features, the differences between some of them were statistically significant. Post-hoc comparisons using Bonferroni indicated that article, conditional sentences, reported speech, relative clauses, and causatives were significantly different. In other words, it was found that tense feature $(\mathrm{M}=3.29, \mathrm{SD}=1.21)$ was significantly different from articles $(\mathrm{M}=2.71$, $\mathrm{SD}=1.01$, $\mathrm{Sig}=.001)$, conditional sentences $(\mathrm{M}=2.77, \mathrm{SD}=1.24, \mathrm{Sig}=.015)$, reported speech $(\mathrm{M}=2.62, \mathrm{SD}=1.20$, $\mathrm{Sig}=.000)$, relative clauses $(\mathrm{M}=3.94, \mathrm{SD}=1.01, \mathrm{Sig}=.000)$, and causatives $(\mathrm{M}=1.96, \mathrm{SD}=1.19, \mathrm{Sig}=.000)$. No more statistical significant differences between "tense" and the other English grammatical features were observed.

When comparing "passive" with the rest of the features, it was revealed that the differences were statistically significant for determiners, relative clauses, and causatives. That is, post-hoc comparisons indicated that passive $(M=2.86, S D=1.37)$ was significantly different from determiners $(M=3.56, S D=1.05, S i g=.000)$, relative clauses $(\mathrm{Sig}=.000)$, and causatives $(\mathrm{Sig}=.000)$. For the remaining features no statistical differences were found.

The same results, as passive, were found to exist for preposition. Therefore, the mean score of preposition ( $\mathrm{M}=$ $3.01, \mathrm{SD}=1.11)$ was significantly different from determiners $(\mathrm{Sig}=.001)$, relative clauses $(\mathrm{Sig}=.000)$ and causatives $(\mathrm{Sig}=.000)$. It was found that verbals $(\mathrm{M}=2.97, \mathrm{SD}=1.16)$ differed significantly from determiners $(\mathrm{Sig}=.000)$, relative clauses $(\mathrm{Sig}=.000)$, and causatives $(\mathrm{Sig}=.000)$. The only difference between article and the last three above-mentioned features was that there was a statistical difference between article and tense features, too. That is, article was significantly different from tense $(\mathrm{Sig}=.001)$, determiner $(\mathrm{Sig}=.000)$, relative clause $(\mathrm{Sig}=.000)$, and causative $(\mathrm{Sig}=.000)$ features. 
The results of conditional sentences indicated that there were statistically significant differences between conditional sentences and tenses ( $\mathrm{Sig}=.015)$, determiners ( $\mathrm{Sig}=.000)$, relative clauses ( $\mathrm{Sig}=.000)$, and causatives ( $\mathrm{Sig}=.000)$. Conjunctions $(\mathrm{M}=3.09, \mathrm{SD}=1.20$, ) were shown to differ significantly from determiners ( $\mathrm{Sig}=.019)$, relative clauses $(\mathrm{Sig}=.000)$, and causatives $(\mathrm{Sig}=.000)$. It was indicated that for reported speech, there were statistically significant differences between this feature and tense $(\mathrm{Sig}=.000)$, determiners $(\mathrm{Sig}=.000)$, relative clause ( $\mathrm{Sig}=.000)$, causative $(\mathrm{Sig}=.000)$, and tag question $(\mathrm{M}=3.09, \mathrm{SD}=1.12, \mathrm{Sig}=.017)$ features.

Based on the obtained results, it was revealed that determiners were statistically and significantly different from passive sentences $(\mathrm{Sig}=.000)$, prepositions $(\mathrm{Sig}=.001)$, verbals $(\mathrm{Sig}=.000)$, articles $(\mathrm{Sig}=.000)$, conditional sentences $(\mathrm{Sig}=.000)$, conjunctions $(\mathrm{Sig}=.019)$, reported speech $(\mathrm{Sig}=.000)$, causatives $(\mathrm{Sig}=.000)$, and finally tag question features $(\mathrm{Sig}=.013)$. In other words, the results indicated that determiners did not differ significantly from just tense and relative clause.

For relative clause, there were statistically significant differences between this and the rest of the English grammar features ( $\mathrm{Sig}=.000$ ), save determiners. When comparing the findings related to causative, the results indicated that there were statistically significant differences between this feature and the other features ( $\mathrm{Sig}=.000)$ with no exception. The results obtained from tag question indicated that the differences between this feature and reported speech $(\mathrm{Sig}=017)$, determiner $(\mathrm{Sig}=013)$, relative clause $(\mathrm{Sig}=000)$, causative, $(\mathrm{Sig}=000)$ features were statistically significant.

\subsection{Instructors' Perceptions of the Difficulty Order of the Given English Grammar Features}

The difficulty order of the given English grammar features determined by experienced instructors was checked to investigate to what extents teachers' understanding of the grammar difficulty was identical with the obtained difficulty order by the EFL learners. The obtained data from the two groups were matched to find out any possible similarities and differences. The results are given in Table 11.

Table 11. EFL instructors' perceptions vs. participants' performances on the features

\begin{tabular}{cll}
\hline Instructors' perceptions & Participants' performances \\
\hline $1-$ & Causatives & Causatives \\
$2-\quad$ Reported speech & Reported speech \\
$3-\quad$ Prepositions & Articles \\
$4-\quad$ Relative clauses & Conditional sentences \\
$5-\quad$ Passive structures & Passive structures \\
6- $\quad$ Conjunctions & Verbals \\
7- $\quad$ Conditional sentences & Prepositions \\
$8-\quad$ Articles & Tag questions \\
9- & Tag questions & Conjunctions \\
$10-$ & Tenses & Tenses \\
$11-$ & Verbals & Determiners \\
$12-$ & Determiners & Relative clauses \\
\hline
\end{tabular}

The hierarchical orders of the given English grammar features based on the instructors' perceptions and the participants' performances were determined. Some similarities/overlaps and differences were seen in the first and the second half of the Table. Causative, reported speech, and passive features were in the first half of the Table, as more difficult features and determiner, tense, and tag question features were in the second half, as less difficult ones.

\section{Discussion}

The order of difficulty of the English grammar features for the Iranian undergraduate EFL learners was determined. The results indicated that causatives, reported speech, articles, conditional sentences, passive structures, and verbals were the six more difficult grammar features. Prepositions, tag questions, conjunctions, tenses, determiners, and relative clauses were proved to be less difficult. The results indicated that causatives was the first and the most difficult feature, the obtained mean score (1.96) was significantly different from all the other English grammar features. The next five grammar features, in the upper half, were more difficult features for the participants; with the mean scores of 2.62 to 2.97 (Table. 8). The other features were in the lower half, with the mean scores of 3.01 to 3.94. It was concluded that there were some English grammar features which were more difficult than others for the EFL learners. The participants showed that they had the least problems with determiners and relative clauses with the mean scores of 3.56 and 3.94 respectively. The obtained results 
indicated that grammar, in general, demands more attention by Iranian EFL learners; although some features were shown to be less difficult than others.

When analyzing the results using post-hoc comparisons, it was found that the differences among the groups (English grammar features) were statistically significant. Seemingly, those features with inadequate practices by EFL learners are more difficult. By taking a look at the obtained hierarchy, it may be claimed that more difficult features have been neglected by EFL learners. Despite studying these features, EFL learners may do not have adequate practices to learn them, and grammar attrition occurs. Moreover, the complexity of the features may add to their difficulty levels. There may be some features which are more demanding in nature than others to learn. Causative, for example, seems to be more complex than other features, and it demands more practice and time to consolidate. It seems that for some of the features, the learners had acquired the rules properly, and they knew how to use them correctly. For instance, in case of relative clause feature, they had fairly good performances. For some other features, EFL learners may have a good mastery of grammar knowledge in some sub-components, but not in others. They may have a good command of indefinite articles, but have problems with definite article. The difficulty order may be because of the complexity of the rules or probably the absence of a particular feature in the mother tongue. The existence or non-existence of some features in the mother tongue may add to the difficulty level (Ellis 2006).

The findings, however, are somehow comparable with Shiu's (2011) findings, who found that Chinese EFL learners perceived prepositions and conditional sentences to be very difficult. In the current study, these features were in the middle of the continuum, with conditional sentences in the first half of the hierarchy. Most of the grammar features used in this study and those by Shiu are not completely identical.

The results contradict parts of the findings by Darus \& Subramaniam (2009) who found that tenses and prepositions were the most difficult features for Malaysian students. In Darus \& Subramaniam's (2009) study, tense and preposition features were in the second and fourth ranks respectively, while in this study preposition was in the seventh rank, and tense in the tenth rank. On the other hand, Darus \& Subramaniam's findings revealed that articles were among more difficult features to learn, and in the current study it was also shown to be difficult to learn, too.

The results, moreover, contradict the findings by Scheffler (2008) who found that tense was the most difficult for Polish EFL learners, and that article was relatively easier for the participants to learn, based on the participants' viewpoints. The results, at the same time, are in line with Scheffler's findings who found that conditional sentences are more difficult.

The comparison between the instructors' perceptions of difficulty order and the undergraduate EFL learners' performances on the given grammar features revealed different orders of difficulty. Therefore, the null hypothesis was rejected. By dividing the Table into first and second half, it was shown that features like causative, reported speech, and passive were in the first half, as more difficult, and tag question, tense, and determiner features were in the second half, as less difficult, for the two groups. For the rest of the features, there were fluctuations in the rank orders of the groups.

A plausible explanation is that EFL instructors have an image of the learners' grammatical knowledge as freshmen in mind; their judgment might have been affected by the problems freshmen students encounter in learning English grammar. They assumed that these problems exist for senior student. Moreover, instructors may find some EFL learners who avoid using particular grammatical features and seek for alternations in their production. The avoided features may be assumed as more difficult by EFL instructors. Another conjecture is that teachers' judgment may be based on the order of presentation of some of the grammatical features as mentioned in some English grammar books. Those materials that are taught earlier may be assumed to be easier to learn, and those that are presented later may be viewed as more difficult, since they require more time and practice to consolidate.

\section{Conclusions}

The current study revealed that some English grammar features were more difficult than others for Iranian undergraduate senior EFL learners, while some others were less difficult to learn. The results may be due to factors including inadequate practice, complexity of the rules, L1 interference, and the same. The findings revealed that the obtained mean scores on most of the grammar features were relatively low. It may suggest that grammar, in general, should be taken into account more seriously. Taking a closer look at the mean scores for the given features, it may be appropriate to classify the features into four categories as very difficult, difficult, relatively difficult, and less difficult: 
-Very difficult features: causatives, reported speech, and articles

-Difficult features: conditional sentences, passive structures, and verbals

-Relatively difficult features: prepositions, tag questions, and conjunctions

-Less difficult features: tenses, determiners, and relative clauses

The results also indicated some similarities and differences in the obtained difficulty orders by the participants and the instructors' perceptions. It was found that there were some similarities and inconsistencies between what instructors assumed as more difficult features and what EFL learners' findings revealed. Therefore, instructors' judgments were not completely consistent with the obtained results by the EFL learners.

\section{Pedagogical Implications}

The findings of the current study may benefit instructors to pay more attention to the English grammar when teaching grammar features to EFL learners. The findings help instructors to have a better understanding of the difficulty order of the features for EFL learners. The most difficult features may be the result of inadequate practice on half of the participants. EFL learners may benefit from the findings, to spend more time and to ask for more tutorial sessions to facilitate the consolidation of difficult features. When both teachers and students are aware of this difficulty hierarchy, they may spend more hours on explaining and offering examples, and may offer remedies and provide some additional comments through different activities (e.g., writing) to facilitate mastering of difficult features. Materials developers may also benefit from the findings. They may include the materials with the emphasis on more difficult features. Providing drills and exercises which specifically address more difficult features may affect consolidation of grammar.

\section{References}

Ahangari, S., \& Barghi, A. H. (2012). Consistency of measured accuracy in grammar knowledge tests and writing: TOEFL PBT. Language Testing in Asia, 2(2), 5-21.

Chuang, Y. (2005). Article misuse: A neglected problem in Chinese EAP student writing. In Proceedings of the Second International Online Conference on Second and Foreign Language Teaching and Research. USA. 25-33.

Darus, S., \& Subramaniam, K. (2009). Error analysis of the written English essays of secondary school students in Malaysia: A case study. European Journal of Social Sciences, 8(3), 483-495.

Ellis, R. (2006). Modelling learning difficulty and second language proficiency: The differential contributions of implicit and explicit knowledge. Applied Linguistics, 27(3), 431-463.

Feike, G. M. (2011). Grammar sequence in basic ESL. Unpublished master's thesis, San Diego State University.

Graus, J., \& Coppen, P. A. (2015). Defining grammatical difficulty: A student teacher perspective. Language Awareness, 24(2), 101-122.

Maros, M., Tan, K. H., \& Salehuddin, K. (2007). Interference in learning English: Grammatical errors in English essay writing among rural Malay secondary school students in Malaysia. e-BANGI: Jurnal SainsSosialdanKemanusiaan, 2(2), 15.

Nan, C. (2015). Grammar and Grammaring: Toward modes for English grammar teaching in China. English Language Teaching, 8(12).

Nassaji, H., \& Fotos, S. (2012). Teaching grammar in second language classrooms: Integrating form-focused instruction in communicative context. TESL-EJ. The Electronic Journal for English as a Second Language, $16(1)$.

Oxford Placement test. (2007). Retrieved Oct. 20, 2015, from http://www.ubd.ua/upload/other-resourses/solutions/solutions-placement-test.pdf?ssid=moyonuowm

Saaristo, P. (2015). Grammar is the heart of language: grammar and its role in language learning among Finnish university students. In J. Jalkanen, E. Jokinen, \& P. Taalas (Eds.), Voices of pedagogical development-Expanding, enhancing and exploring higher education language learning (pp. 279-318).

Sadighi, F. (2008). English grammar: Oriented approach. Navid Shiraz Publication. Iran.

Sawir, E. (2005). Language difficulties of international students in Australia: The effects of prior learning experience. International Education Journal, 6(5), 567-580. Retrieved March 12, 2016, from http://files.eric.ed.gov/fulltext/EJ855010.pdf 
Scheffler, P. (2008). Rule difficulty and the usefulness of instruction. ELT Journal Advance Access, 1-8.

Shiu, J. L. (2011). EFL learners' perceptions of grammatical difficulty in relation to second language proficiency, performance, and knowledge. Unpublished doctoral Dissertation, University of Toronto. Retrieved Jan. 12 , 2016, from https://tspace.library.utoronto.ca/bitstream/1807/29869/1/Shiu_LiJu_201106_PhD_thesis.pdf

Wang, F. (2010). The necessity of grammar teaching. English Language Teaching, 3(2), 78-81. Retrieved March 25, 2016, from http://files.eric.ed.gov/fulltext/EJ1081617.pdf

Wang, Sh. (2010). The significance of English grammar to middle school students in China. Journal of Language Teaching and Research, 1(3), 313-319. Retrieved March 25, 2016, from http://dx.doi.org/10.4304/jltr.1.3.313-319

Widodo, H. (2006). Approaches and procedures for teaching grammar. English Teaching, 5(1), 122-141.

Zhang, J. (2009). Necessity of grammar teaching. International Education Studies, 2(2), 184-187. Retrieved March 15, 2016, from http://dx.doi.org/10.5539/ies.v2n2p184

\section{Copyrights}

Copyright for this article is retained by the author(s), with first publication rights granted to the journal.

This is an open-access article distributed under the terms and conditions of the Creative Commons Attribution license (http://creativecommons.org/licenses/by/4.0/). 